\title{
BIOACCUMULATION OF HEAVY AND ESSENTIAL METALS IN TROPHIC LEVELS OF POND ECOSYSTEM
}

\author{
N. PARVEN AND M.A. BASHAR \\ Department of Zoology, University of Dhaka, Bangladesh \\ AND \\ S.B. QURAISHI \\ Chemistry Division, Atomic Energy Centre, Dhaka-1000, Bangladesh
}

\section{ABSTRACT}

Bioaccumulation of heavy and essential metals was examined in duckweed (first trophic level) and in a pyralid insect larva (second and successive trophic level) in two different ponds e.g. organic and inorganic ponds. Hospital's waste-materials and inorganic fertilizers were used as duckweed nutrients in organic pond and inorganic pond, respectively. A total of 24 water, duckweed and insect samples were used for analysis of essential and heavy metals. Toxic metals were found to transmit and persist in duckweed. The insect is a duckweed consumer in pond ecosystem. Persistence of heavy metals and essential metals was evidenced in the insect when its larval stages were examined. Nine heavy/essential metals $(\mathrm{Pb}, \mathrm{Cd}, \mathrm{Cu}, \mathrm{Co}, \mathrm{Mn}, \mathrm{Ni}, \mathrm{Cr}, \mathrm{Fe}$ and $\mathrm{Hg}$ ) were analyzed by atomic absorption spectrophotometer (AAS). All of these trace metals were greater in evidence in organic pond than the inorganic pond. Some heavy and essential metals did not bio-accumulate from duckweed to insect larval body. Some toxic metals such as Lead, Copper, Manganese and Cobalt were evidenced at high concentration in water, duckweed and insect larvae. The experimental results indicated that persistence of heavy/essential metals occurred in successive trophic levels of pond ecosystem.

Keywords: Duckweed, pyralid insect, heavy and essential elements, bio-accumulation, pond ecosystem, trophic level

\section{INTRODUCTION}

The biotic factors of an ecosystem are eternal and ever ending wealth for the planet. Some toxic metals (heavy and excess amount of essential metals) act as key factors for changing biotic community of an ecosystem. In recent years there has been a growing concern on the increase of heavy metals contamination which affect the terrestrial and aquatic environments ${ }^{1,2,3}$. There has been an increasing realization on the role of trace metals in human food ${ }^{4,5}$. In present investigation, duckweed productivity in a pond ecosystem was studied in view to examine sustainable duckweed production. The duckweed species growing in different types of aquatic habitats are mostly affected by organic pollutants ${ }^{6}$. Duckweed appears promising for removing heavy and toxic metals from wastewater. When trace and heavy metals are available in water bodies, they act as nutrient for duckweed growth. If the first trophic level (the duckweed) absorbs essential and heavy metals by its roots and fronds, those are passed along the food chain and finally accumulate at higher concentrations that become hazardous to natural ecosystem as well as to the consuming animals health. The sampling location for collection of surface water, duckweed and pyralid larvae were selected on the basis of appropriate environmental significance. PRISM (Project of Rural Industry, Science and Medicine) a nongovernmental organization at the Mirzapur Kumudini Hospital Complex (Tangail, Bangladesh) cultures duckweed for wastewater treatment of the hospitals and domestic and municipals waste materials. These duckweeds are also used as fish food. In the present study, the water samples, duckweed, and insect larvae were used to examine the levels of heavy and essential metals and bioaccumulation process of these metals from the 
duckweed to the insect. In the tests, both the experimental insect and duckweed feeding fishes were found to occupy the same trophic level. The herbivore fishes and insect (pyralid larvae) consume duckweed as food directly. The objective of this study was to determine the heavy metals absorption process by the pyralid larvae through water and duckweed.

\section{EXPERIMENTALS}

Surface pond's water $(500 \mathrm{ml})$ was collected by dipping one litter capacity of white plastic bottle. All the bottles and containers were previously washed with deionized water and $20 \%$ nitric acid properly. Duckweed mass and pyralid larvae were collected by metallic sieve $(6.35 \mathrm{~cm} \times 6.35 \mathrm{~cm})$ and stored in $11.43 \mathrm{~cm} \times 8.89 \mathrm{~cm}$ plastic containers. Surface water, fresh duckweed mass and pyralid larvae were collected from the same pond. A total of 24 samples of water, duckweed (plant) and insect larvae (pyralid) were collected at 15 days intervals from the selected sites of the selected pond from June 2006 to August 2006. Water, duckweed and the insect larval samples were preserved in a refrigerator until preparation and analysis.

The collected water samples were acidified with $2 \mathrm{ml} \mathrm{HNO}_{3}$ as early as possible after collection; $250 \mathrm{~mL}$ acidified water samples were evaporated to pre-concentrate at 10 to $15 \mathrm{ml}$ on the hot plate at $90^{\circ} \mathrm{C}$.

Duckweed mass were washed properly with deionized water (DI). After removal of the extra water properly by table lamp, the initial weights were taken. Duckweed samples were dried in an oven under $100^{\circ} \mathrm{C}$ for two hours and grained properly by Carbide motor. The grained duckweed samples were ashed by heating in Muffle furnace for 6 hours. The duckweed ash was than digested with $4 \mathrm{ml}$ aqua regia $\left(3: 1\right.$ of $\mathrm{HCl}$ and $\mathrm{HNO}_{3}$ ). The solution was evaporated nearly to dryness on hot plate with watch glass under $100^{\circ} \mathrm{C}$ temperature for 3-4 hours. Finally, 2-3 drops of concentrated nitric acid were added and final volumes were made to $10 \mathrm{ml}$ with DI. Samples were also diluted before analysis if required (e.g. Fe and Mn).

The larval samples were washed properly with Deionized water. Then extra water was removed and kept 2 hours for air dry. After drying, the samples were ashed in a Muffle furnace for about 6 hours at $450^{\circ} \mathrm{C}$. Then the samples were digested with $2 \mathrm{ml}$ nitric acid on hot plate at $100^{\circ} \mathrm{C}$ for $3-4$ hours until the colour changed to white. The final volume was made to $10 \mathrm{ml}$ with DI.

A Parkin-Elman Atomic Absorption Spectrophotometer (model 3110) was used for determination of the quantities of $\mathrm{Pb}, \mathrm{Cd}, \mathrm{Cr}, \mathrm{Co}, \mathrm{Ni}, \mathrm{Mn}, \mathrm{Fe}$ and $\mathrm{Cu}$.

\section{RESULTS AND DISCUSSION}

Nine heavy and essential metals such as Lead, Cadmium, Cobalt, Chromium, Mercury, Nickel, Manganese, Iron and Copper in the water, duckweed and pyralid insect larval samples were determined by atomic absorption spectrophotometric method. The concentrations of the essential and heavy metals in organic pond samples were higher than the inorganic pond samples due to direct connection of sewage, drainage effluents like domestic, municipal and hospital wastes.

The study attempted to assess the heavy and essential metals concentrations and bioaccumulation process within water, plant and insect. The metal's concentrations were 
found to increase from water to duckweed; but from duckweed to insect larvae, the toxic metals were not transmitted significantly due to short exposure or contamination period of the insect with duckweed (larval period was about 16- 21 days). It is evident that if the toxic metals are released to the pond, it is transmitted in the successive trophic levels (plants and animals) from the pond water having detrimental effects. Both the essential and non-essential metals are toxic to living organisms when subject to high concentrations. The concentrations of Lead, Cadmium, Copper, Cobalt, Nickel and Manganese were found to vary in water, sediment and fish ${ }^{7}$.

Lead: Lead $(\mathrm{Pb})$ was detected in both pond (organic and inorganic) water and duckweed samples but it was below the detection limit in the insect larvae collected from both the ponds. The total concentrations of $\mathrm{Pb}$ in organic water and duckweed samples $(6.38 \mathrm{ppb}$ and $4.26 \mathrm{ppm}$ respectively) were higher than in inorganic pond samples (3.15 ppb and $3.86 \mathrm{ppm}$, respectively) (Fig.1).

Cadmium: In the both (organic and inorganic) waters and larvae, Cadmium was found

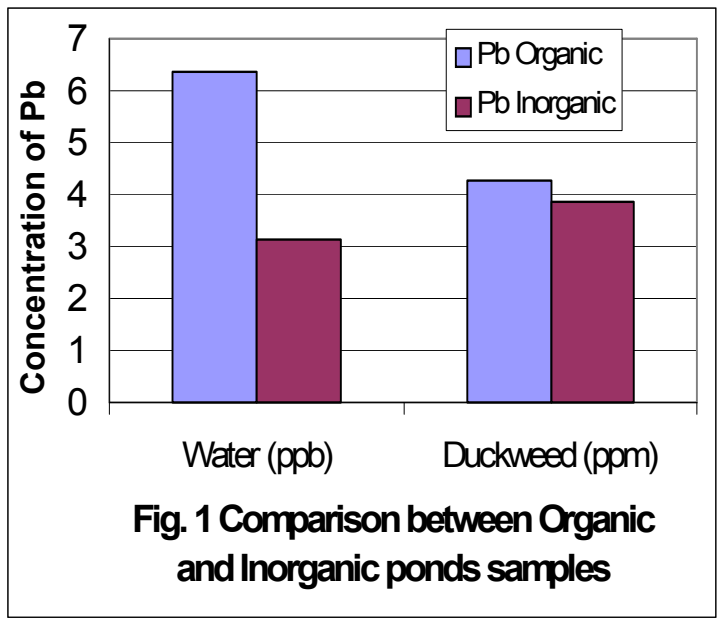

below the detection limit. Cadmium was only found in inorganic duckweed sample (2.02 ppm). In the organic samples, it was below the detection limit. Lemna it el. (duckweed spp.) is a potential biomarker of heavy metal pollution. The duckweed spp. Lemna is also used for the removal of some heavy metals (Lead, Cadmium, Chromium, Zinc, Copper and Mercury) ${ }^{8}$.

Copper : It is also an essential nutrient but at higher level may cause human diseases. There was a clear difference in the total concentrations of Copper in water, duckweed and insect larvae of both organic and inorganic samples. The levels of Copper in organic water and duckweed samples were found to be $15.55 \mathrm{ppb}$ and $6.13 \mathrm{ppm}$, respectively and these concentrations were higher than those of inorganic samples $(6.13 \mathrm{ppb}$ and 4.64 ppm, respectively). In case of insect larvae, the copper level was also found higher in organic $(2.47 \mathrm{ppm})$ than in the inorganic pond (1.44 ppm), which is presented in the Fig. 2. Duckweed was found suitable for aquatic toxicity test and utilized to study the growth responses and accumulation of Chromium in the presence of Copper and Zinc'. 


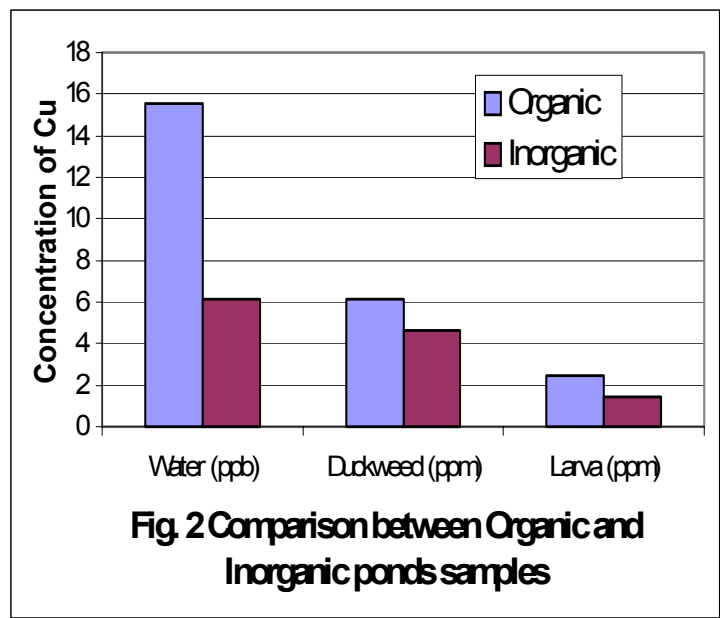

Iron: Iron is an essential element for living plant and animal metabolism. But the excess amount of Iron is toxic for both the plants and animals. The concentrations of Iron in both organic and inorganic samples were found extremely high. It is seen in fig. 3 that the total concentrations of Iron in inorganic water and duckweed were $2090 \mathrm{ppb}$ and $878 \mathrm{ppm}$, respectively, the values were almost sirieler in organic water (1996 ppb) and duckweed (884 ppm). In insect samples the concentrations of Fe were also almost equal (2.38 ppm and $2.20 \mathrm{ppm}$ ) in organic and inorganic samples.

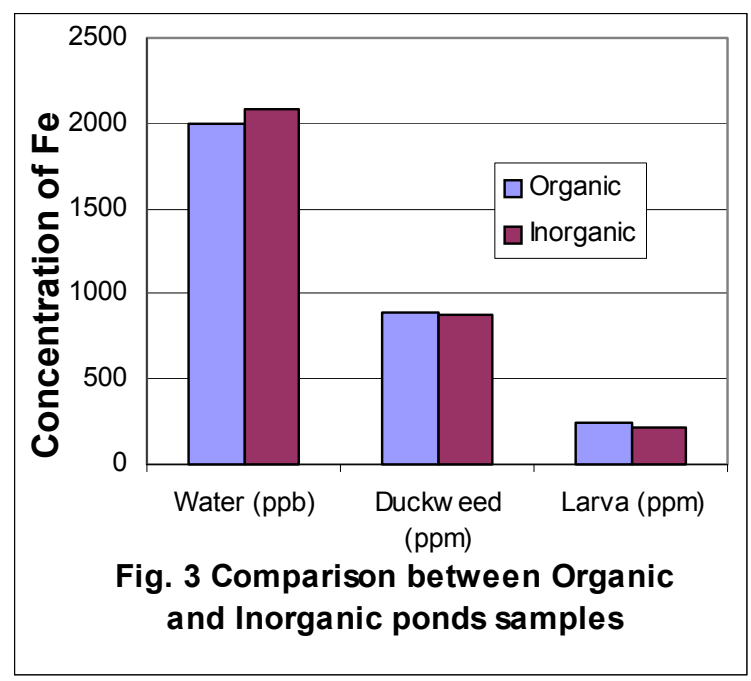

Manganese: The concentrations of Manganese in water, duckweed and in insect larvae of the organic pond were found to be $109 \mathrm{ppb}, 213 \mathrm{ppm}$ and $23.39 \mathrm{ppm}$ respectively; those were much higher than in inorganic water (59 ppb), duckweed (107.2 ppm) and insect larvae (12.30 ppm) samples. The results have been presented in Fig. 4. It is reported that 
the heavy and essential metals $(\mathrm{Zn}, \mathrm{Cu}, \mathrm{Mn}, \mathrm{Fe}$ and $\mathrm{Pb})$ can be accumulated from water to shrimp $^{10}$.

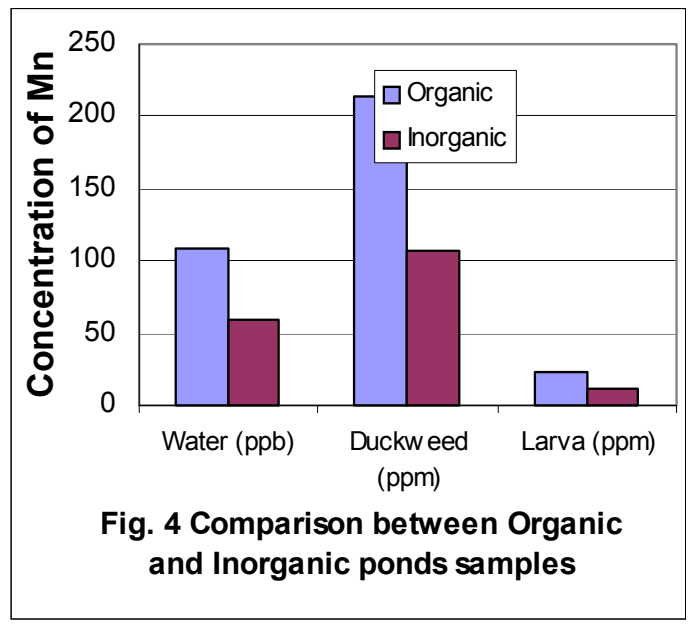

Nickel: Total Nickel (Ni) concentration in inorganic water (5.44 ppb) was almost equal to that of the organic one $(4.78 \mathrm{ppb})$. In case of duckweed, total Ni concentration was found to be $18.11 \mathrm{ppm}$ and $19.01 \mathrm{ppm}$ in organic and inorganic ponds, respectively. The concentration of Nickel in Pyralid larval samples was $1.06 \mathrm{ppm}$ in the organic samples and $1.2 \mathrm{ppm}$ in inorganic larval samples as seen in Fig. 5. Heavy metals are of great environmental concern due to their potential problem associated with their toxicities. Some essential micronutrient such as $\mathrm{Mn}, \mathrm{Cu}$ and $\mathrm{Ni}$ although necessary, often may cause toxicity ${ }^{11}$.

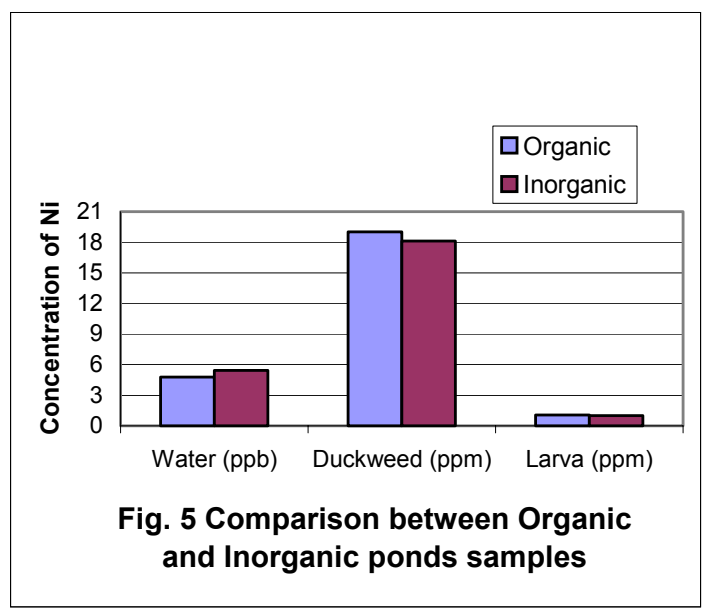


Chromium: The total concentration of Chromium $(\mathrm{Cr})$ in organic water samples was found higher $(5.0 \mathrm{ppb})$ than that of the organic water samples $(2.94 \mathrm{ppb})$. Chromium was not found in duckweed and pyralid insect larval samples in both the ponds.

Mercury: Mercury ( $\mathrm{Hg}$ ) was not detected in duckweed and insect larvae of both the ponds' samples. The total concentration of $\mathrm{Hg}$ in organic water samples was $1.3 \mathrm{ppb}$ but in the inorganic water samples it was $0.82 \mathrm{ppb}$. The Chromium and Mercury levels are presented in Fig.6. The concentrations were much higher in organic pond due to the direct sewage connection, drainage effluent like domestic, municipal and hospital wastes to this pond.

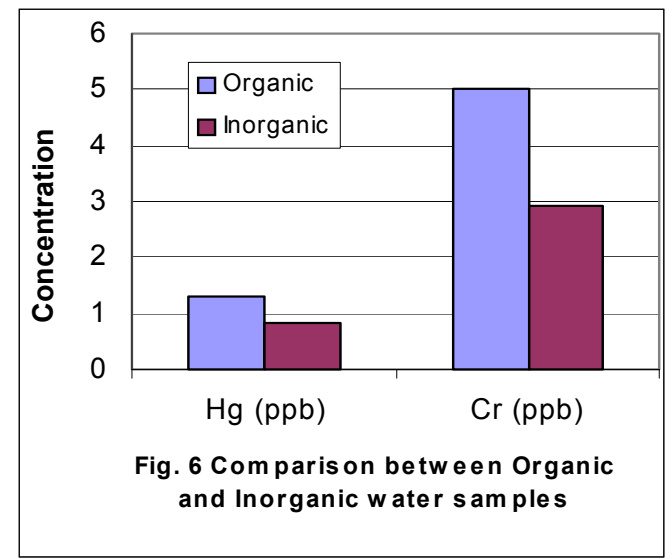

Cobalt: Cobalt (Co) may cause damage to the liver, kidney, circulatory and nerve tissues due to long-term exposure. In the organic pond, the Pyralid larvae, duckweed and water samples, showed higher concentration of Co compared to the inorganic pond. These differences are shown in the Fig. 7. 


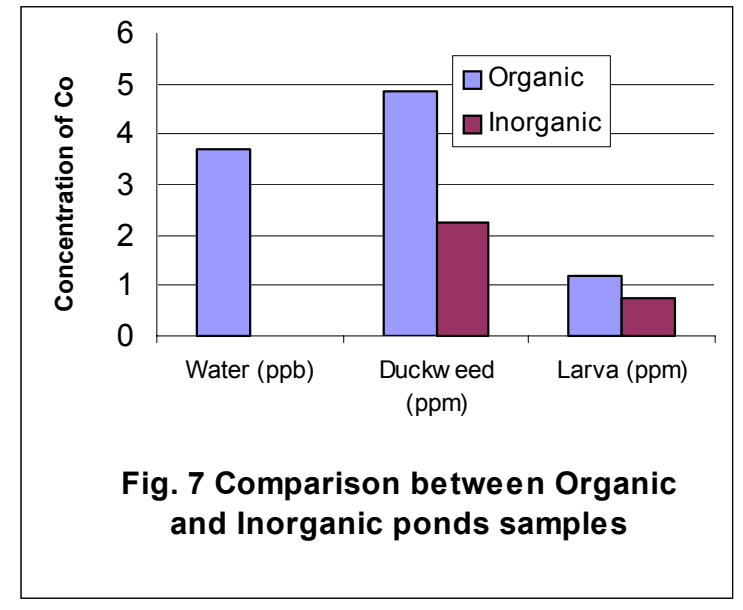

Significant high concentration level of a pollutant could elicit adverse effect on the living process of an organism ${ }^{12}$. When heavy metals such as $\mathrm{Cu}, \mathrm{Ni}$ and $\mathrm{Zn}$ are accumulated in the soil, these can be taken up by the plants and re-enter the food chain, which cause a long-term environmental hazard ${ }^{13}$. Toxicant interactions are common occurrences in a number of aquatic ecosystems and the toxicant may cause physiological damage of the respiratory structures as well as may affect other vital organs that can lead to death ${ }^{14}$.

4. Conclusion

The data presented in the paper provide information on heavy and essential metals absorption by duckweed and bio-accumulation of the metals in pyralid insect through duckweed. When duckweed absorbs toxic metals from the cultured habitat and if it used as herbivorous fish food, the toxic metals can be bio-accumulated. The experimental results indicated that the concentrations of all heavy and essential metals were higher in the organic wastewater pond samples than in inorganic samples. The hospital, domestic and municipal wastes were probably the source of these toxic metals in water, duckweed and pyralid insect. The transmition of the toxic meals in the successive higher trophic levels like duckweed to insect body, gives an important indication of bioaccumulation of these metals.

\section{References}

1. A. Schutz, S. Ranstam, S. Skerfving and S. Tejning, Ambio 13, 115. 1984.

2. N. I. Ward, J. M. Savage, SCI. Total. ENVIRON. 146. 390, 1994.

3. R. J. Hares, PH. D. Thesis, Chemistry, UK, UNIVERSity of SURREY. 387. 2000.

4. M. KhandKer, A. K.M. Nurul and Z. N. T. Begum, BANG. J. Bot. 19(1), 51, 1990.

5. E. J. Underwood, TRACE ELEMENTS IN HUMAN AND ANIMAL NUTRITION, ACAdEMIC PRESS: NeW YORK, 1971.

6. V. Volkovic, Trace Element ANalysis, TAYLOR AND Francis LtD.; LONDON, 1975. 
7. A. KASChL, V. ROMHELD AND Y. CHEN, SCI. TOTAL. ENVIRON. 35(3). 403, 2002.

8. S. Mukherji, S. Mukherji, P. Bhattacharyya And A. K. Duttagupta, ENVIRON Int. 30(6), $811,2004$.

9. D. Neylen, and D. Fulya, Toxicology and ENVIRonmental SAFETy, 53(3), 397. 2002.

10. S. B. SAHA, NUCL. SCI AND APPI., 81(1), 106, 2003.

11. S. Xu, and S. TOA, SCI. TOTAL ENVIRON. 320, 73. 2004.

12. H. Y. Ming, ENVIRONMEN. TOXICOL, LEWIS PUBLISHER: NEW YorK, 2001.

13. N. BARLAR, ENVIRON. TOXICOL. 14(1), 367. 1998.

14. J. Herrmann and K. G. Anderson, Water. Air. Soll. Pollut. 30, 527. 1986.

Journal of Bangladesh Academy of Sciences, Vol. 33, No. 1, 131-137, 2009 